Penultimate Draft. The final and definitive version of this paper is forthcoming in $\underline{\text { Synthese. }}$.

\title{
Memory and Epistemic Conservatism
}

\author{
Matthew McGrath
}

\section{Introduction}

We are all conservatives, at least when it comes to belief retention. We are forgetful, of course, but we typically do not abandon our beliefs unless we have special reasons to do so. Our conservativeness might be viewed as a kind of deep self-trust, or less nobly, as simply part of the “inertial" character of belief (Harman 1986, Owens 2000). Whichever view one takes of the psychology, an epistemological question arises: if a subject $S$ believes that $p$, does the retention of that belief thereby have some positive epistemic status for $S$, at least prima facie? An epistemic conservative is someone who answers this question in the affirmative. Conservatives may disagree about more specific matters, e.g., about which positive epistemic statuses (justification, blamelessness, rationality, etc.) satisfy a conservative principle or about how broadly to construe the range of defeating conditions associated with the prima facie rider. But the core of the doctrine is the epistemic efficacy of belief.

In this paper, I will defend a form of conservatism about rational belief retention. I focus on rationality mainly for two reasons. First, this notion is regularly employed in ordinary epistemic evaluations of belief (arguably unlike justification). Second, rational belief retention does not require that one's belief be true, and so does not require knowledge, truth-tracking, safety, or other truth-entailing externalist statuses. Conservatism with respect to these statuses is a non-starter, at least under any reasonably narrow construal of the range of defeating conditions. 
My argument in favor of conservatism is not a variant of familiar ones based on considerations of cognitive efficiency (see Harman 1986 on "clutter avoidance" and also Lycan 1988) or based on the need to avoid skepticism in general (Chisholm 1989) or the need to cope with the evidential underdetermination of theories (Sklar 1975). Rather, I will argue that epistemic conservatism makes a good epistemology of memory. More particularly, I will argue, first, that the two standard accounts of the rationality of memory belief, preservationism and evidentialism, face insuperable problems, and second, that conservatism, properly honed, avoids those problems and incurs no unacceptable commitments. I make the case against the standard accounts in sections I and II, and defend conservatism against objections in section III. What will emerge is a moderate form of conservatism that is fundamentally an epistemological principle about memory.

Before proceeding, certain terminological matters require brief discussion. Epistemologists often ask questions about a subject's rationality (justification, etc.) with respect to the statics of belief (e.g., is $S$ rational to believe that $p$ ? Is $S$ rational in believing/having the belief that $p$ ?), rather than the dynamics of belief (e.g., is $S$ rational to retain/abandon the belief that $p$ ?) However, in ordinary life we regularly use the language of rationality when discussing belief dynamics, and it is clear that the sort of rationality involved is epistemic rather than moral or prudential. Suppose I receive an email from my friend containing the message that he will not be able to join me for lunch today as we had arranged. Then I am rational to abandon my belief that the two of us will have lunch and not rational to retain it. In this case, we can agree that I am rational to abandon my belief that I will have lunch with my friend and not rational to retain it. Moreover, we would not apply the term 'rational' because abandoning my belief would 
maximize my expected utility, nor because it is morally required, but because it is proper in a distinctively epistemic sense. ${ }^{1}$

Even granting that an epistemic notion of rationality applies to belief retention, we might ask about the relationship between that application and the more standard static applications. Can the truth-values of the dynamic claim ' $S$ is rational to retain the belief that $p$ ' and the static claim ' $S$ believes that $p$ and is rational to believe that $p$ ' ever diverge? In what follows, I will assume that the answer is no. Thus, I will freely interchange the two, as well as the corresponding pair ' $S$ is rational to abandon the belief that $p$ ' and ' $S$ believes that $p$ but is not rational to believe that $p^{\prime}$. This policy is convenient because most of the literature we will discuss employs the standard static terminology. Readers who are skeptical of these equivalences should understand what follows entirely in terms of the rationality of belief retention and abandonment. For those are the key notions for our project. At crucial places in the paper, we will return to the explicitly dynamic assertions.

\section{Preservationism}

Memorial belief is belief retained from an earlier acquisition. ${ }^{2}$ The fact of this special connection to the past, unshared by other sorts of beliefs, might encourage the thought that

\footnotetext{
${ }^{1}$ It is notoriously difficult to give an informative characterization of distinctively epistemic positive statuses, whether rationality, justification, responsibility, etc. Among the leading accounts are Feldman's (2001) role-based account (distinctively epistemic 'oughts' are role-oughts, where the relevant role is that of a believer), Fumerton's (1995) probability-based account (distinctively epistemic justification requires that a proposition be probable for a subject), and Foley's $(1993,2001)$ goal-based account (distinctively epistemic rationality is a matter of how well a belief that $p$ seems from one's perspective to serve the goal of now having an accurate belief on whether $p$ ). Whichever of these accounts we adopt, the example given in the text succeeds: I am rational in the distinctively epistemic sense to abandon my belief about lunching with my friend.

${ }^{2}$ In this paper, I use the term 'memory belief' to apply to retained beliefs. My usage of 'memory belief' is the same as Senor's (2005), with the exception that I (like Burge) allow beliefs that remain occurrent over a period of time to count as memory beliefs. My usage of 'memory belief' (and Senor's, too) may not fit particularly well with talk of 'remembering that $p$ ' in ordinary language. When we remember our original evidence for $p$, we do not typically say we remember that $p$. Dokic (2003) raises a slightly different issue. He gives the example of originally thinking what one sees is only a hologram "book" and then later, after being told that there was no hologram, forming the
} 
whether a subject is rational in holding a memory belief depends on whether the belief was rationally formed. This is preservationism. The view is not new with Burge (see also Malcolm 1963, Locke 1971, Annis 1979), but he gives it arguably its best articulation and defense. Much of this section will focus on his work.

Burge argues that what he calls preservative memory, i.e., that faculty which preserves contents, together with their force, for further use by the subject, also preserves rationality (1993, 462). ${ }^{3}$ He is chiefly concerned with the role of memory in temporally extended argument, in which one first accepts premises and later reinvokes them to establish conclusions. Over the course of an argument, he claims, preservative memory must retain not only belief (content+attitude) but also epistemic status, if one is acquire a rational belief in one's conclusion. Burge's claim about the role of memory in extended argument does not by itself have implications for the role of memory in other circumstances. It does not, in particular, imply that if I was originally rational in forming a belief and I simply retain the belief in memory without acquiring new confirming or infirming evidence, then when the belief occurs later in my thought or reasoning I remain rational in holding it. After all, there need be no continuous or discontinuous episode of reasoning connecting the original acquisition of the belief and its later use. Nevertheless, Burge (1997, 39-40) has endorsed this broader view, and understandably so. For he does not think that the way memory preserves rationality in extended argument is by preserving those mental states which originally conferred rationality. Such a view would lead

belief that one saw a book. Can't we call the resulting belief a memory belief, despite the fact that it is just being formed? Our main arguments will be unaffected by these terminological issues.

${ }^{3}$ Two points here. First, I am formulating Burge's claims in my own preferred terminology of rationality. Burge's terminology is a bit different. For him, 'warrant' is the general term, under which falls both justification (in the sense of having reasons accessible to the subject) and entitlement (which is an epistemic right to accept a proposition the ground for which need not be accessible to the subject). Burge is a preservationist about warrant because he is a preservationist about entitlement. Second, Burge sometimes seems to define preservative memory in terms of warrant-preservation. But it is useful to establish terminology which will make it possible to ask nontrivial questions about the epistemic role of memory. Preservative memory is the power of retaining beliefs and other content-possessing mental states. 
one to think that, when one's original belief was based on reasons, then as soon as one forgot one's original reasons, one would need new reasons. This is the result Burge most wants to avoid. According to Burge, rationality can be preserved over the course of an argument simply by virtue of the belief's having been retained by the subject. The epistemically relevant factor is retention, not retention over the course of an argument.

The view that we are attributing to Burge can be formulated as follows:

Preservationism: one is prima facie rational in holding a memory belief if the belief was acquired rationally, and prima facie irrational if it was acquired irrationally.

A few clarificatory remarks here. First, by 'irrational' we simply mean not rational rather than 'incoherent' or the like. Second, we understand the 'prima facie' rider narrowly, in terms of the having of "special reasons": what can defeat one's prima facie rationality is the having of special reasons to give up the belief; and what can defeat one's prima facie irrationality is the having of special reasons to hold the belief. We will take special reasons to include neither standard philosophical justifications for relying on memory (e.g., "I seem to remember that $p$; what I seem to remember is reliable; etc.”) nor standard skeptical justifications for not relying on memory (e.g., “I don't know my memory isn't malfunctioning, and if I don't know that, then I don't have knowledge of what I seem to remember, and if I don't have knowledge of what I seem to remember, I shouldn't accept what I seem to remember.”). Third, note that preservationism does not require, for rational belief, that the factors which originally conferred rationality on a subject's belief still do so when the belief is a memory belief. Burge himself seems to endorse this view, ${ }^{4}$ but a preservationist might claim instead that what makes the subject rational (irrational) in holding a memory belief is the fact that it has been preserved from

\footnotetext{
${ }^{4}$ One reason not to endorse this view is that even a subject's possession of very strong evidence against her original evidence does not necessarily make the subject rational to abandon a belief, if the subject has forgotten the original evidence.
} 
an original rational (irrational) acquisition. Here retentive memory is not purely enabling; it is part of what confers epistemic status.

Preservationism has counterintuitive consequences. Suppose it turns out that when you originally acquired a certain belief about a matter of fact, e.g., that Hannibal fought in the third Punic war, you were not rational to form it (e.g., you had a good reason for doubting your interlocutor's reliability - your interlocutor being your six year-old son, say). And suppose the belief is now a memory belief. Having forgotten your original evidence, as you do for most of your beliefs, and having acquired no new special evidence for or against the belief, you are prepared to retain it. You do know some things about the Punic Wars, of course. You know there were three of them, that Rome fought Carthage in them, etc. The Hannibal belief, however, is not only false but poorly formed. If preservationism is true, then you are not rational to hold this belief. This is what is counterintuitive. Recall that our focal epistemic concept is rational belief retention. Your Hannibal belief is not knowledge - it is false, for one thing, and unreliably formed for another - but you are rational to retain it. To deny you are rational to retain it commits one to claiming that you are rational to abandon it. But this seems clearly wrong. You were not rational when you formed the belief, but you are now rational to retain it. Certainly, you violate no rational requirements in retaining it. In fact, it might be more plausibly argued that you would violate rational requirements by abandoning it. ${ }^{5}$

Some will immediately object that we are playing fast and loose with 'rational'. You are blameless in holding onto the Hannibal belief - they will say - but not rational to do so. Perhaps you could in some relevant sense do no better than to hold onto the belief, but rationality requires

\footnotetext{
${ }^{5}$ Huemer's (1999) dualistic theory holds that one's memory belief is justified iff it was formed and maintained properly. While this theory improves on preservationism in certain ways, it has the same implausible consequence for the Hannibal example. For, in the example you are rational in holding your Hannibal belief even though it fails to meet at least one of the conditions the dualistic theory requires for justification (because it was improperly formed). However, perhaps Huemer would distinguish justification from rationality.
} 
more than this. Someone ignorant of the fallaciousness of gambler's fallacy reasoning might blamelessly form and retain a belief based on such reasoning, but he would not be rational to do so. He can perhaps do no better than to be irrational. ${ }^{6}$

My reply is two-fold. First, you are not merely blameless in retaining the Hannibal belief; retaining the belief is rationally appropriate for you. Rational entitlement to retain a belief does not require that the belief had a good origin. The Hannibal belief is every bit as rationally appropriate to your current perspective as are most pieces of historical knowledge. Think of it this way. Whether it is rational to retain or abandon a belief at a time is a matter of which of these makes sense in light of your current epistemic perspective, i.e., in light of what you currently have to work with in revising your beliefs. ${ }^{7}$ It makes as little sense, in light of your current perspective, to abandon the Hannibal belief as it does to abandon most instances of your historical knowledge. I assume that you are not rational to abandon whole swathes of your historical knowledge. And so, I conclude that, contrary to preservationism, you are not rational to abandon the Hannibal belief. ${ }^{8} 9$

\footnotetext{
${ }^{6}$ One might argue that the converse fails as well, i.e., that rational belief retention needn't be blameless. If I believe that believing $p$ is irrational, then even if I'm wrong (and believing $p$ is rational), I might deserve blame for retaining my belief that $p$.

${ }^{7}$ For discussions of the perspectival character of rationality (and justification), see Foley (1993, 2001) and Kvanvig (2003). The notion of a perspective, although intuitive and regularly employed in contemporary epistemology, deserves closer scrutiny. For our purposes, a perspective can be thought of a set of contemporaneous mental states, including beliefs, experiences, sensations, intuitions, etc. Which beliefs count? All? only occurrent beliefs? only "activated" beliefs? These are questions that need to be answered. As Goldman points out, if I know that the library has different hours on Sunday but show up there because I didn't think about it, was I being rational in forming the belief that the library will be open at 10am today? If the unaccessed knowledge is part of my perspective (and just as much a part as the beliefs I explicitly considered, then I am not rational. But this seems too harsh a judgment. What is most important for our point against preservationism is that information that is not believed, even dispositionally, is not part of one's perspective.

${ }^{8}$ Note the following contrast. We regularly say, in defense of retaining a belief, "I had no reason to abandon it." We do not regularly say, in defense of abandoning a belief, "I had no reason not to abandon it." But what would the preservationist suggest you say, in defense of yourself, when you give up a belief such as the Hannibal one? It is hard to think of an answer besides, "I had no reason not to abandon it." But even putting aside the fact that we don't regularly give or accept this sort of defense, it seems the preservationist shouldn't endorse it. For, if you are then asked, "Ok, but doesn't that mean you have no reason not to abandon your belief that there were three Punic Wars?" what could you say other than "Yes"? If this is what you must say, then it seems you are forced to concede, "I have
} 
Second, even if we were to concede that in the example you are merely blameless, rather than positively rational, in retaining the Hannibal belief - something which we should not concede - an interesting question remains concerning what accounts for your blamelessness. The blamelessness is neither moral nor prudential, but epistemic. Preservationism is then a poor theory of this blamelessness. If evidentialism, too, founders on the blamelessness of certain memory beliefs, then we would have reason to think hard about a conservative account. Conservative factors, in other words, might still have an important role in the epistemology of memory. ${ }^{10}$

One might reply to my critique of preservationism as follows. "You are stacking the deck against preservationism by insisting that the relevant notion of rationality is the rationality of subjects. Obviously that isn't preserved by retention of rational beliefs, nor is the irrationality

no defense - I abandon the one but not the other, period." A subject who (by luck!) abandons just those beliefs which preservationism entails she is rational to abandon must see her many of belief revisions as arbitrary.

${ }^{9}$ My argument holds for a number of other interpretations of rationality. Audi (2001, 49-55) distinguishes several notions of rationality applicable to particular beliefs. One is the minimal notion: a belief is minimally rational iff it is not irrational. (This use of 'irrational' is to be read as stronger than our use of it as meaning not rational.) Another notion, which Audi claims is more commonly employed in ordinary thought, is what he calls the approbative notion: a belief is rational iff it is consonant with reason. He finally mentions a notion of rational requiredness. In terms of this spectrum of notions, I would claim that the Hannibal belief is rational in both the minimal and approbative senses, and that it is even plausible to claim that it is rational even in the sense of rational requiredness. One might argue that we are rationally required to retain such beliefs because we are not rationally permitted to abandon them.

${ }^{10}$ There would of course be no need for any theory of epistemic blamelessness if one was automatically epistemically blameless whenever one could not have abandoned one's belief. Here the issue of doxastic voluntarism arises. However, even if a person could abandon the Hannibal belief, I submit that retaining it would be epistemically blameless. If this is correct, we then need an account of what, if not the inability to abandon the belief, makes retaining it blameless. Here conservatism, but not preservationism, is in the running.

In developing such a conservative account of epistemic blamelessness, one would need to respect certain subtleties. Arguably, it seems possible for a person to be blameworthy for having a belief but not for retaining it. The person might have the belief now because he was careless yesterday, but if he is presently not careless and lacks any recollection of his prior carelessness, he might be blameless for retaining the belief, though blameworthy for having it. If so, conservatism will be more plausible as a theory of the blamelessness of retaining the belief rather than that of having it. For more on the subtleties of blameworthiness and responsibility, see Kornblith 1988. 
of a subject preserved by the retention of irrational beliefs. Preservationism is a plausible theory of the rationality of beliefs but not of the rationality of subjects in having or retaining beliefs." 11

I reply as follows. First, if preservationism is a nonstarter as a theory of a subject's rationality, then all to the good; my argument is easier than I had imagined. Second, I admit that a subject can be rational to abandon a belief which, as it turns out, was rationally formed and maintained (as when the subject possesses new defeaters), and similarly, that a subject can be rational to retain a belief which, as it turns out, was irrationally formed or maintained (as in the Hannibal case). But I do not see how rationality could be an attribute of anything but subjects, and so I see talk of rational beliefs as explainable in terms of talk of a subject's rationality in having or retaining beliefs.

In reply, a preservationist might lean heavily on a proper basing requirement for a subject's rationally believing something. It is standardly assumed that a subject rationally believes that $p$ only if the subject is not only rational in believing that $p$ but believes that $p$ on the basis of some factor that makes her rational in believing it. The claim would then be that, in the Hannibal case, because your basis for your memory belief is the poor evidence you had at the time of acquisition, and because this is not a proper basis, you do not rationally believe it now, even though you may well be rational in continuing to believe it.

I am not sure how to think of the basing relation in connection with memory beliefs. ${ }^{12}$ However, it is highly questionable to claim that, in the Hannibal case, your basis is the original long-forgotten evidence. That evidence plays no current role in the sustaining of your belief, and

\footnotetext{
${ }^{11}$ Owens (2000) claims rationality is two-dimensional in this sense. It has a diachronic dimension applying to beliefs and a synchronic dimension applying to subjects.

${ }^{12}$ One might say that memory beliefs are based on memory, but the difficult question is then what it is to be based on memory. Is it to be based on certain peculiarly memorial experience? or simply to be memorial, i.e., retained? We will touch upon these issues briefly in Section II.
} 
its undermining would not make you rational to abandon your belief. ${ }^{13}$ More cautiously, I would say this: either your basis in the Hannibal case is not the original forgotten evidence or else proper basing isn't in general necessary for rational believing.

It is worth noting that Burge himself is unwilling to tolerate the implausible consequences of preservationism as applied to testimonial belief. ${ }^{14}$ In the case of testimony, he distinguishes the recipient's proprietary warrant, which consists of all entitlements and justifications available to the recipient for accepting the proposition presented-as-true by the testifier, from the extended body of warrant, which includes not only the recipient's proprietary justification but that of the testifier as well as anyone else in the testimonial chain (1993, 485-6). This allows him to accommodate the strong intuition that a recipient of testimony who relies on a source that lacks entitlement can nonetheless be entitled to believe what she is told. For Burge, the extended body of warrant is indeed relevant to whether the recipient gains knowledge and to the status of that knowledge as a priori or a posteriori, but not to whether the recipient has entitlement.

Jim Edwards (2000) cites this disanalogy between Burge's epistemologies of testimony and memory as a problem and suggests two possible solutions. The first is to embrace the disanalogy and support it by citing key differences between memory and testimony. The second, which Edwards favors, is to restore the analogy by bringing the epistemology of testimony into alignment with that of memory: a recipient is not entitled to believe what she is told if the original source had no warrant.

\footnotetext{
${ }^{13}$ Suppose Mr. X, a family friend from your childhood, originally told you that Florence Nightingale pushed for nursing and medical reforms during the Crimean war. You've now forgotten where you acquired this information. You have no reason to think it came from Mr. X. You then learn that Mr. X is unreliable. I take it that this information does not make you rational to abandon your belief about Nightingale.

${ }^{14}$ Preservationism applied to testimonial belief holds that a recipient is prima facie rational in a testimonial belief if the source is rational, and prima facie irrational if the source is irrational. Burge, as I read him, implies a contrast between memorial and testimonial entitlement in his reply to Christensen and Kornblith (1997). See Burge (1997, 39-40).
} 
One wonders, however, why we cannot distinguish between a subject's proprietary

warrant for a memory belief and the extended body of warrant, which includes the subject's past warrants. We could then distinguish the conditions that memory beliefs must meet to count as knowledge (and to count as knowledge of a certain kind: a priori vs. a posteriori) from the conditions memory beliefs must meet for their subject to be rationally entitled to them. In other words, we might favor a third possibility neglected by Edwards: restore the analogy by bringing Burge's epistemology of the memory into alignment with that of testimony. ${ }^{15}$

We will return to this third possibility below. For now, we have pointed out the unacceptability of preservationism. We turn next to evidentialism.

\section{Evidentialism}

Evidentialism is a general theory about epistemic rationality and yields a thesis about memory beliefs as a special case. According to evidentialism, a subject is rational in believing that $p$ iff

\footnotetext{
${ }^{15}$ Burge gives an argument for the claim that memory preserves original warrant (in the sense of rational entitlement). If the argument is sound, then our way of restoring the analogy between memory and testimony is unacceptable.

Suppose that an individual is warranted in believing a premise by thinking it through and understanding it. The individual's later reinvoking the premise to take a new step presupposes that the warrant for the reinvocation is the same as the original warrant. Otherwise, the individual would have to begin the argument again by establishing the premise. If purely preservative memory cannot be relied upon to preserve not only the content but the warrant for the earlier instantiation of the step, the individual cannot proceed with the argument. (2003b, 301)
}

Burge tells us that 'presupposition', as he uses the term, does not denote a propositional attitude. Rather, states can be said to presuppose that $p$, where a state presupposes that $p$ iff "a metaphysically necessary condition on being in the state is that $p$ and this condition can be arrived at by mature reflection on the conditions that make that state possible [though the reflection needn't be from the individual's perspective]" (2003b, 293).

I am not sure how precisely to formulate Burge's argument, in light of his stipulated meaning for 'presuppose'. (Reinvoking a premise does not metaphysically entail anything about whether it is or was warranted.) We can say this, however: the conclusion's deriving warrant from the inference presupposes that the premises are warranted. But it is unclear how it follows that the warrant for the premises when reinvoked must be the original warrant.

One might suggest that when the step is questioned, we will not refer to memory but rather to our grounds for the step. This is not necessarily true. If last week I established that $p$, and this week I reason from $p$ and other premises to $q$, I might not remember my proof that $p$. If asked about $p$, I will reply that I proved it last week. I will not reply by giving my original grounds.

Of course, it also matters here what sort of epistemic status is under consideration. I do not dispute Burge's claim that knowledge depends on the extended body of warrant. 
believing $p$ fits the evidence the subject has (Feldman and Conee 1985, 2001). We may add that, for evidentialists, which doxastic attitude fits the evidence is a matter of the strength of one's evidence for the truth of $p$. This holds not only for the three attitudes of believing, withholding, and rejecting, but also for more and less confident forms of believing. So, for example, I have extremely good evidence right now for the proposition I am seated, much better evidence than I now have for it will rain later this week. Perhaps in both cases believing fits my evidence, but only in the former case does believing with great confidence fit my evidence.

Evidentialism can be divided into two kinds, depending on the kinds of evidence acknowledged. The first is a doxastic evidentialism, which allows as evidence only beliefs. The second is nondoxastic evidentialism, which, as the name suggests, allows more than simply beliefs as evidence. ${ }^{16}$ We will look at each in turn.

\section{Doxastic Evidentialism}

Let us begin by distinguishing between two types of doxastic evidence a subject might have for a proposition $p$ : first- and second-order. Your second-order evidence for $p$ is rooted in evidence about your memory in respect of $p$. More carefully, $e$ is a piece of your second-order evidence for $p$ iff $e$ is evidence you have for $p$ and either, (i), $e$ itself, in its content, is about your memory in respect of $p$ (i.e., $e$ could be about either your currently remembering that $p$, your seeming to remember that $p$, or your having a memorial experience that $p$ ), or else, (ii), $e$ owes its own epistemic status (as rational) to your possession of evidence that is about your memory in respect of $p$. Your first-order evidence for $p$ is just your evidence for $p$ which is not secondorder.

\footnotetext{
${ }^{16}$ There is some awkwardness in referring to beliefs as evidence (rather than propositions). There are ways to reduce this awkwardness (see Haack 1995 on S- vs. C-evidence), but not much will hinge on these matters.
} 
Here is an example of each. If you can now give Einstein's reasoning for the conclusion that simultaneity is not absolute, you have first-order evidence for that proposition. Your evidence here is remembered, but that doesn't bar it from being first-order. The crucial point is that the evidence is not itself about your memory in respect to $p$ and doesn't depend for its epistemic status on your having evidence that is. In this case, your first-order evidence concerns the relevant subject matter, i.e., invariant speed of light, etc. But it need not. So long as your evidence that Mr. X told me that $p$ doesn't depend epistemically on evidence about your remembering, seeming to remember, or having a memorial experience that $p$, then it can be firstorder evidence for you for $p .^{17}$ By contrast, if you do not recall what Einstein's reasoning was or who told you about the relativity of simultaneity, you might still have second-order evidence in favor of this proposition, e.g., that you remember it to be the case.

First-order doxastic evidence seems inadequate to account for our rationality in holding many of our memory beliefs. We often have such evidence when we first form beliefs. But, as Gilbert Harman $(1986,41)$ has stressed, we tend to forget our evidence (in the first-order sense) for our retained beliefs even though we may still be highly rational in having them. This is what he calls the problem of "forgotten evidence." When I think about my knowledge that there were three Punic Wars, I am hard-pressed to provide much first-order evidence. I can tell you other facts about the Punic Wars, and sketch an extremely rough story of the wars. But the pieces of my Punic Wars story, even if narratively coherent, do not together provide much evidence for there being exactly three of them. ${ }^{18}$ They certainly do not provide the very strong evidence that

\footnotetext{
${ }^{17}$ This isn't first-order for you for $p$ if its epistemic ancestry consists in reasoning like this: I remember that $p$; the only person I could have learned this from is $\mathrm{Mr}$. X, and so Mr. X must have told me that $p$.

${ }^{18}$ Or think of your knowledge that Napoleon proclaimed himself emperor. Imagine swapping this belief for the belief that Napoleon reluctantly accepted the crown. If your knowledge of Revolutionary France is sketchy enough, the coherence of the resulting story will be nearly unchanged by the swap. But you are rational in having the one belief but not the other.
} 
is necessary, given evidentialism, to make me rational in holding this belief as confidently as I do. Indeed, it seems I have stronger first-order evidence for my belief it will rain later this week (having just looked at the forecast). But I am not rational to hold this belief as confidently as my belief about the number of Punic wars. So, it seems that our rational entitlement to confidentlyheld memory beliefs cannot be explained by appealing only to our first-order evidence for them.

Can second-order evidence plug the gap? Typically, if asked about a memory belief, we appeal to our memory. Consider my belief about the Punic Wars. Asked why I believe this, I might simply reply "I remember there were three." But is I remember $p$ really evidence for $p$ ? Some would say "no," on the grounds that $e$ can be evidence for $p$ only if $e$ doesn't presuppose $p$. Others would reply that the evidence-for relation needn't match up perfectly with the dialectics of justification: $e$ might be evidence for $p$ even if it would be illegitimate, even questionbegging, to appeal to $e$ in favor of $p$. We needn't enter into this debate. We can instead ask the evidentialist what evidence one has for I remember $p . p$ itself is little evidence for I remember that $p$. Presumably, at this point, the evidentialist will turn to the evidence about seeming memory. But what evidence do I have for the proposition I seem to remember that $p$ ?

It is well-known that doxastic evidentialism has difficulty accounting for the rationality of our psychologically noninferential beliefs about our own mental states. Opening my eyes and looking, I come to be rational in non-inferentially believing this looks red. How could this be explained solely in terms of my doxastic evidence? What evidence do I acquire for this looks red by opening my eyes? It is hard to see how this new evidence could be anything but certain features of the experience itself, and this would be nondoxastic evidence. The same sort of worry arises in the case of memory. Turning my mind to the question, 'what's the capital of Nevada?', I come to be rational in thinking I seem to remember it is Reno. What new evidence 
do I acquire which explains this fact? The evidentialist naturally answers this by appealing to the seeming memory itself.

A second and more fundamental problem is that doxastic evidentialism seems to demand too much of its subject. A young child can have rational memory beliefs, while lacking not only in first-, but also second-order evidence. That is, the child may lack (even the capacity to form) the relevant beliefs about her cognitive attitudes toward the proposition she believes. ${ }^{19}$ This problem is of course familiar from the epistemology of perceptual belief. A young child can have rational perceptual beliefs without having or being capable of having the relevant secondorder beliefs about how things look, etc. So, at least, it appears. One would not want to hedge one's epistemological bets on a speculative and likely false claim about the higher-order intellectual powers of young children. ${ }^{20}$

Because of these problems, evidentialists standardly move from doxastic to nondoxastic evidentialism.

\section{Non-doxastic evidentialism}

A popular sort of nondoxastic evidentialism about memory holds that we enjoy quasiperceptual states which make our memory beliefs rational (cf. Conee and Feldman 2001, Fumerton 1995, Pollock 1974, 1986). ${ }^{21}$ On this view, there is a kind of seeming memory that isn't explained in terms of belief or dispositions to believe, and which may be called memorial

\footnotetext{
${ }^{19}$ The phenomenon of "childhood amnesia," first noticed by Freud, has been taken to cast doubt about young children's capacity for episodic or personal memory but not for factual memory. See Baddeley 1999, ch. 12.

${ }^{20}$ For a forceful recent critique of "intellectualist" models in epistemology, see Burge 2003a. See also Feldman (forthcoming).

${ }^{21}$ Our talk of seeming memory here and throughout is talk of seeming factual memory. We are speaking of the phenomenology distinctively associated with factual memory beliefs when we attend to them. Seeming episodic memory does surely consist, at least in part, in the having of memory images of objects, properties, and events.
} 
experience. Just as states of perceptual experience can make perceptual beliefs rational, so states of memorial experience, which are relevantly similar, can make memory beliefs rational.

The quasi-perceptual account is attractive for several reasons. First, the epistemology of perceptual belief, although hardly undisputed, is fairly well understood. To the extent that states of seeming memory are analogous to states of perceptual experience, we can see how they could constitute nondoxastic evidence. Second, in abandoning the appeal to second-order evidence, we avoid over-intellectualization because we are not supposing that subjects have or are always capable of having beliefs about memory. Third, the quasi-perceptual account provides us with a way to bring Burge's epistemology of memory into alignment with his epistemology of testimony. In having a memorial experience that $p, p$ is presented as true to us and is intelligible to us. The Acceptance Principle:

A person is a priori entitled to accept a proposition that is presented as true and that is intelligible to him, unless there are stronger reasons not to do so. $(1993,469)$

would therefore extend to memorial as well as testimonial belief. ${ }^{22}$

The main difficulty for nondoxastic evidentialism, as is well-known, is to give an account of memorial experience that is consistent with the phenomenology of memory beliefs or the lack thereof. We often (but not always!) undergo memory phenomenology when we recall some events, people, and objects (whether concrete physical objects or not, e.g., poems, symphonies), and sometimes also when we recall certain facts. But it cannot be seriously maintained that distinctive memorial phenomenology attends all of the memory beliefs we are rational to hold, even all our occurrent ones. A memory belief may occur in an episode of conscious reasoning without having any such phenomenology.

\footnotetext{
${ }^{22}$ In personal communication, Burge remarked that he intended the Acceptance Principle to apply only to interlocution or testimony.
} 
In response, one might claim that at least all memory beliefs have this feature: if one lacks memorial phenomenology associated with it, then at least one is disposed to have such phenomenology upon making the belief not merely occurrent but also the object of conscious attention. This claim might then be used to explain our rationality in holding memory beliefs for which we lack the phenomenology. The idea is to count one's disposition to enjoy memorial phenomenology for such a belief as evidence one has for the belief.

But, as Alvin Goldman (1999, 278-9) argues, having the disposition to have evidence for $p$ is not sufficient for having evidence for $p$. One might have the disposition without having any evidence at all. One may have forgotten that $p$, but be disposed, when asked precisely about $p$, to undergo memorial phenomenology which by hypothesis would make it rational to believe that $p$. ("Is it true that your childhood home phone number was xxx?" "Why yes!") In such a situation, before being asked, one is not rational to believe that $p$. And so one's being disposed to have evidence must not be a way of having the evidence. If it was, then one would be rational. ${ }^{23}$

Alternatively, the evidentialist might say that, concerning memory beliefs which aren't objects of attention, we can be said to be rational in holding them only in a secondary and derivative sense: we are rational insofar as we are disposed to be rational (in the primary sense) in holding them upon making them the objects of our attention. The strategy, then, is to invoke a secondary sense of 'rational' which does not require the actual having of evidence but merely the disposition to have evidence.

Any such account would need to be refined to avoid counterexamples. Attending to a belief can have all sorts of effects, one of which might be to acquire evidence one previously

\footnotetext{
${ }^{23}$ Note here that in response to Goldman one cannot plausibly invoke a dispositional/occurrent distinction with phenomenological states. Phenomenological states may or may not be attended to or noticed, but they are always occurrent; they figure in their subject's consciousness. Unnoticed pain is one thing; a nonoccurrent dispositional pain (as opposed to a disposition to have a pain) is quite another. If seeming memory is phenomenological, then there is no such thing as nonoccurrent seeming memory.
} 
lacked or to lose evidence one previously had. But there are other problems. I mention two.

The first is a basic conceptual problem. We noted above that the disposition to have evidence is not by itself a way (e.g., a "secondary" way) of having evidence at all. Nor is having the disposition to be rational by itself a way of being rational. Merely having dispositions to have epistemic perspectives of certain kinds is not sufficient for having them and so cannot affect rationality directly. The second concerns evidential chains among beliefs. Often we are rational to hold a belief we are attending to only because of evidence we aren't attending to. Suppose my wife shows me a photograph of one of my identical twin sons. I say, “That's a great picture of Thomas with the mountains in the background." I can't tell pictures of the twins apart. What makes me rational in forming the belief in this case is my background knowledge that I took Thomas, and not his twin brother, on a trip to the mountains. ${ }^{24}$ Now, in cases like these, we either say that we are rational $p_{p}$ (i.e., in the primary sense) in holding the background belief or that we are merely rational (i.e., in the secondary sense) in holding it, or in other words, that we are disposed to be rational . If we say the latter, then it is difficult to see how our holding the

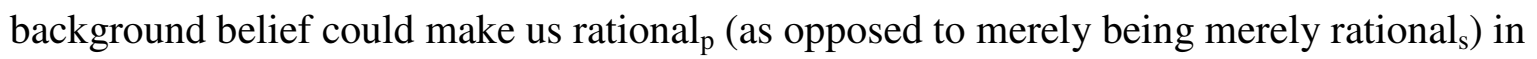
forming the focal belief. If we say former, then we face the problem of identifying the evidence that makes us rational $\mathrm{p}_{\mathrm{p}}$. No memorial experience need be present. The mere disposition to have such experiences is not itself evidence for the belief. It seems there is no evidence for the background belief, or at best only doxastic evidence for it. But, as we saw above, doxastic evidence often seems to be in too short a supply.

\footnotetext{
${ }^{24}$ Senor (2005) claims that all background beliefs are memory beliefs. Given our working definition of 'memory belief' (see note 2), this is true at least if unrevised but "content-updated" beliefs count as retained beliefs. For example, consider my belief that there is a park on north side of town. I don't merely believe that there was one, but there is one now. We can call such beliefs retained beliefs and so memory beliefs, but we should be alert to the possibility that the epistemology of such beliefs may not perfectly match that of memory beliefs which are not "content-updated."
} 
Perhaps the most fundamental problem for the quasi-perceptual approach is the significant disanalogy between seeming to remember that $p$ and having a perceptual experience as of things being that $p$. There are differences in both form and content. With respect to form, unlike perceptual experience but like belief, seeming memory does not essentially contain a presentational element: the objects, properties, and events that make up the content of what we seem to remember do not seem to be there before us. So, for example, my seeming memory that Hannibal was a Carthaginian does not involve any apparent presentation of a person in the way that an apparent visual experience of a person does. This presentational difference can help explain why there is a persistent temptation to postulate special mental objects of hallucination but no similar temptation to postulate special mental objects of beliefs or seeming memories about what does not exist. ${ }^{25}$ If Macbeth doesn't see a real dagger, it is still tempting to say that there is a mental dagger in his visual field or at least to say that dagger-like features are instantiated in his visual field. By contrast, should we find out that 'Homer' is an empty name, we would feel no pressure to find a special mental version of Homer to make sense of our Homer-related beliefs and seeming memories.

As for content, there is no range of events, properties and objects distinctive to the content of seeming memory, as there is for perceptual beliefs. I can have a memory belief with just about any kind of content, even (obviously) a purely mathematical content. I can seem to remember, for example, that a certain equation has two solutions.

These differences in form and content are important to bear in mind when considering whether epistemological arguments about perception can be extended to memory. One familiar argument in the epistemology of perception is that perceptual experience counts as nondoxastic evidence because of the existence of constitutive relations between the experience's content, the

\footnotetext{
${ }^{25}$ This contrast between "empty" beliefs and hallucination is noted in Johnston 2004.
} 
relevant objects and properties in the world, and the content of the belief. Such a thesis is far less plausible for seeming memory, given that it can have any content whatever. Elizabeth Fricker (unpublished) makes a parallel point regarding testimony.

John Pollock (1986) claims that one can seem to remember something that one doesn't believe and even believes is false and then proceeds to argue on the basis of this claim for a strong analogy between seeming to remember and perceptual experience. However, the possibility of seeming memory without belief can be explained without viewing seeming memory as analogous to perceptual experience. If one has believed for many years that there were, say, three Peloponnesian wars and only one Punic war, and one then is informed that there was only one of the former and three of the latter, one can still feel the residual effects of one's prior convictions: "I've always believed that. I'm stunned I was wrong!" Part of the phenomenology of surprise is a felt inclination to continue believing. ${ }^{26}$

Let me mention one final difficulty for the perceptual analogy. Perceptual experience does not merely provide evidence; it serves as a basis on which we form perceptual beliefs. We can distinguish $p$ 's being rational for a subject due to the subject's having certain perceptual evidence, from a subject's rationally believing that $p$ on the basis of that evidence. However, memory beliefs are not typically quasi-inferential in this way (cf. Shoemaker 1972). When we use our memory beliefs in reasoning and thought - and in fact often when we reflect on them explicitly - we do not base them on evidence at all, at least in anything like the way in which we base our perceptual beliefs on how things look, sound, etc. This is not to deny that sometimes we do form beliefs based on memorial imagery ("Yes, I can see it, Sally was at the party after

\footnotetext{
${ }^{26}$ It might be noted that not every case of being inclined to believe that $p$ but not believing that $p$ is a case of seeming to remember that $p$. This is surely correct. It is difficult to explain what more is involved in seeming memory. Plantinga $(1993,59)$ invokes an idea of pastness: when I seem to remember that $p$, my belief, or my inclination to believe (if I do not have the belief), has a kind of pastness about it - it is familiar.
} 
all") or even on the basis of seeming factual memory ("Sally must have been at the party; I don't remember seeing her there, but I just seem to recall that she was there"). But by 'memory belief' we have in mind retained beliefs rather than newly formed ones. Retaining a belief is not typically a matter of basing a belief on evidence. ${ }^{27}$

Given these problems with a quasi-perceptual account, an evidentialist might propose a doxastic account of seeming to remember that $p$. There are a number of options here, but they all involve a strong connection between seeming to remember that $p$ and believing or being inclined to believe not only that $p$. The hope might then be to retain evidentialism by claiming that seeming memory, so conceived, is nonetheless evidence for memory beliefs.

An obvious difficulty for this proposal is that the return to cognitive states as evidence seems to be a return to doxastic evidentialism, with its attendant problems. Perhaps these worries can be mitigated, but one wonders what the point is, once seeming memory is understood doxastically. Isn't it simpler and more natural to abandon the evidentialist gambit and turn to conservatism?

\section{Conservatism}

Conservatism holds that if one believes that $p$, then one is prima facie rational in retaining that belief. $^{28}$ Given its permissiveness, conservatism escapes the problems facing preservationism and evidentialism. Given a relatively narrow understanding of the range of defeating conditions

\footnotetext{
${ }^{27}$ There is an important distinction here between mere counterfactual dependence and basing. Suppose my retained belief that Hannibal was a Carthaginian becomes occurrent. It could well be that, had I not also seemed to remember that this was the case, I would have abandoned the belief. This does not imply that I based my belief on the seeming memory. Similarly, from the fact that, had you not seemed sincere to me when you told me that $p$, I would not have formed the belief that $p$ upon hearing you, it does not follow that my belief is based on your seeming sincere to me.

${ }^{28}$ One might explore even broader views than conservatism. For example, we might add to conservatism the principle that Huemer (2001) calls "phenomenal conservatism," according to which if it seems to $S$ that $p$, then $S$ is prima facie justified in believing that $p$.
} 
for the prima facie rider - a range that includes only the possession of special reasons to abandon belief - your Hannibal belief can be rationally retained, and no first- or second-order evidence is needed to ground your being rational to retain that belief or other beliefs for which you have forgotten your original evidence.

But conservatism, too, has its problems and may prove unacceptable despite its advantages. My approach in this section will be to address what I regard as the three best objections to it and suggest possible ways to stave them off. In so doing, I will suggest ways of refining and grounding conservatism. The three objections are the "epistemic partiality" objection (Christensen 2000)— conservatism wrongly privileges our own beliefs over others' beliefs; the "conversion" objection (Foley 1983, Senor 1993, Burge 1997, Huemer 1999, Sosa 1999, and Christensen 2000)_conservatism implausibly allows mere belief to make one rational in believing something when one previously wasn't; and the related "extra boost" objection (Foley 1983, Huemer 1999) — conservatism implausibly allows mere belief to provide an extra epistemic boost to a subject who, prior to forming a belief that $p$, already was rational in believing that $p$.

\section{The partiality objection}

David Christensen (2000) has argued that conservatism wrongly privileges the believer's own beliefs over others' beliefs and so is epistemically partial. His argumentative strategy is to first give a counterexample to conservatism and then appeal to epistemic partiality as part of a diagnosis of why conservatism fails. We will discuss the counterexample and the diagnosis, in turn.

Here is the downloader case: 
Suppose that I have a serious lay interest in fish, and have a fairly extensive body of beliefs about them. At a party, I meet a professional ichthyologist... I don't want to trouble her by asking a lot of work-related questions. Fortunately, I have a beliefdownloader, which works as follows: If I turn it on, it scans both of our brains, until it finds some ichthyological proposition about which we disagree. It then replaces my belief with that of the ichthyologist and turns itself off... (358)

Concerning the case, Christensen holds that (a) - (c) are all true:

(a) the subject's putative prima facie rationality to retain his belief is not defeated.

(b) coherence considerations aside, the subject has an epistemically reasonable option for changing his beliefs, viz. downloading.

(c) The subject should download.

From these premises, he draws the conclusion that epistemic conservatism and "diachronic coherence" principles are one and all incorrect. Among these are included not only conservatism but probabilistic conditionalization, and Van Fraassen's principle of "reflection."

Let us grant, concerning the downloader case, that (a) and (c) are true. We then have two questions.

Question \#1: Is (b) true?

Question \#2: If (b) is true - and so if (a) - (c) are all true - does it follow that epistemic conservatism is false?

Consider Question \#1. Is downloading an "epistemically reasonable option for changing your beliefs"? Here we must beware talk of "options for changing your beliefs." This is ambiguous between talk of action resulting in belief revision and talk of revising your beliefs (and so abandoning a belief and forming an incompatible belief). If we take the former interpretation, we may agree that (b) is true. But so read, we must answer the Question \#2 negatively; (a) - (c) do not establish the falsity of conservatism. The latter implies only that, in the absence of defeaters, you are rational in retaining your belief; it does not imply that you have an epistemic 
requirement to resist courses of action that will (or might) result in your belief that $p$ being given up.

Consider the following humdrum counterpart of the downloader case. You're at the party, considering whether to ask the ichthyologist questions about fish. If you ask, then during the course of the conversation it is very likely that you will revise some of your beliefs about fish (you will do the revising, rather than a machine). What should you do? Given your interest in knowing more about fish, the answer is ask. But the fact that you should ask doesn't show that when you're standing there thinking about asking the ichthyologist questions you aren't rational to retain your first-order beliefs about fish. Suppose the belief that you will revise, over the course of the conversation, is that scrod is a species of fish. (This belief is false.) Does your realizing that by asking the ichthyologist you will improve your knowledge about fish undermine the rationality of your belief about scrod? Not at all. ${ }^{29}$

Alternatively, we might understand talk of "option to change one's beliefs" in terms of revising belief. The trouble now is that this entails that we must answer Question \#1 negatively, because (b) is false; for, you aren't reasonable or rational in the epistemic sense to revise your first-order beliefs about fish. You have no special reason to doubt any of these beliefs. One could insist that nonetheless you ought to revise them, both in the downloader case and the question-asking case. But that is just to beg the question against conservatism. ${ }^{30}$

\footnotetext{
${ }^{29}$ An anonymous referee asks whether Christensen could still argue that if conservatism is true, then because your beliefs are already prima facie rational, downloading is just a waste of time, and so you aren't rational to do it. However, consider the case of asking the ichthyologist a question: if your beliefs are prima facie rational, why bother asking? The answer, in both cases, is that being better informed about fish is more important to you in the situation than merely having rational beliefs about fish. In general, while having rational beliefs is certainly epistemically valuable, it is not the only epistemic value, and in some cases, the prospects of other epistemic values (knowledge, true belief, etc.) can give one practical reason to do something which will lead to the abandonment of a previously rational belief.

${ }^{30} \mathrm{My}$ response presupposes a distinction between belief revision and courses of action leading to belief revision. I have suggested that downloading really is a course of action, no different in kind from asking questions, and so is
} 
In the absence of other reasonable interpretations of 'option for revising one's beliefs',

we conclude that the counterexample fails.

On the assumption that the downloader example succeeds, Christensen identifies what he takes to be the fundamental error contained in conservatism and the whole family of diachronic coherence principles. They violate the deep principle of Epistemic Impartiality.

The considerations determining which beliefs it would be epistemically rational for an agent to adopt do not give special status to any of the agent's present opinions on the basis of their belonging to the agent $(2000,363-4) .{ }^{31}$

Conservatism wrongly makes the fact that your beliefs are yours relevant to the question of what you should believe. Or so the claim is. Note that this objection does not depend on the success of the downloader example and so deserves a separate response.

However, one need not take conservatism to be a foundational epistemic principle. It can be grounded by appealing to the Reidian principle that we are prima facie entitled to presume, of any belief, that it is well-formed and well-maintained and so is worthy of trust. This Reidian principle itself might be grounded further, perhaps, as Burge $(1993,472)$ would have it, by

something quite different from belief revision. But what if the downloader worked instantaneously? Wouldn't it amount to belief revision? This strikes me as highly implausible.

But, for the sake of argument, suppose that downloading is belief revision, and in particular that downloading in this case amounts to revising the belief that scrod is a species of fish. I would still want to insist on the difference between a subject's being practically rational in downloading/revising and being epistemically rational in doing so. Practical rationality is a matter of the expected value of retaining the belief in light of its consequences for all one's goals. Epistemic rationality, if it to be explained in terms of goals at all, would have to be explained (à la Foley) in terms of the expected promotion of the goal of one's now having an accurate belief with respect to the particular proposition in question. Before downloading you have every reason to think your general goal of learning more about fish would be satisfied by downloading. And since this is the most important goal in the situation, we can see how you would be practically rational to download/revise. But before downloading you have very weak reason indeed for thinking that by downloading you would improve your accuracy on whether scrod is a species of fish. You have only as much reason for thinking this as you have for thinking that one of your first-order beliefs about fish is false. And that isn't much. So, before downloading, even if epistemic rationality is to be explained in terms of goals, and even if downloading amounts to belief revision, you are not epistemically rational to download/revise.

${ }^{31}$ The fact that Christensen takes conservatism to violate Epistemic Impartiality confirms the suspicion that he fails to distinguish believing or adopting a belief from doing something that leads, or can be expected to lead, to a belief's being adopted. 
appealing to putative a priori relations between content, belief, rationality, and truth. ${ }^{32}$ Whether the conservative is willing to accept the full Burgean grounding or only a more limited Reidian one, she is immune from the charge of epistemic partiality. Accepting conservatism is perfectly consistent with claiming that it is not the fact that the belief is mine which ultimately makes it worthy of my trust but the fact that it is a belief. ${ }^{33}$ Conservatism does not entail partiality.

There is a further reason, apart from avoiding the commitment to epistemic partiality, to provide a Reidian or Burgean grounding for conservatism. It helps to explain why having reasons to think that one's belief was poorly formed or poorly maintained can defeat one's prima facie rationality to retain one's belief. A reason to think a belief that $p$ is poorly formed or maintained is obviously not necessarily a reason to think that $p$ is false. It is not necessarily, in John Pollock's terminology, a rebutting defeater. Rather, such a reason undercuts the prima facie rationality to hold the belief by giving one reason to doubt that the grounds for that prima facie rationality obtain. This sort of defeat is something common to epistemologies invoking prima facie epistemic statuses. The reliabilist, for example, will want to say that the prima facie

\footnotetext{
${ }^{32}$ In grounding conservatism in this fashion, the conservative is not supposing that every subject who is rational to retain her belief, due to her holding the belief, must also be rational in accepting the sophisticated propositions figuring in the grounding of her rationality in believing that $p$. Burge emphasizes this point concerning his Acceptance Principle.

There remain difficult questions about how to understand the talk, in the grounding of the Acceptance Principle, of a belief's being prima facie well-formed and maintained. Prima facie for whom? A higher animal or small child who is entitled to the belief need not have the conceptual repertoire to think about the formation and maintenance and so need not be entitled to believe anything about such matters. And which attitude is the subject prima facie entitled to take - a belief, or something else?

On the latter question, we may say that the subject is entitled to presume or take for granted that the relevant proposition complicated proposition is true. To presume that $p$ does not require having the concepts constitutive of $p$ and so does not require believing that $p$, but rather involves being disposed to conduct one's cognitive and practical affairs in some of the ways distinctive of a person who believed that $p$. If you presume that $p$, you are disposed, for example, not to doubt whether $p$ and to act as if $p$ is true (i.e., approximately, to do the act A iff $\mathrm{A} \& p$ is preferable to all combinations of the form $\mathrm{B} \& p$, where $\mathrm{B}$ is an available competitor to $\mathrm{A}$ ).

${ }^{33}$ In trusting someone else's a belief, I rely on my awareness of it inferentially or at least quasi-inferentially (I base my belief on my belief about or awareness of your belief), whereas when I trust myself by retaining a belief I do not typically make any inferences. But this limited self-other asymmetry is to be expected.
} 
justification to hold a perceptual belief can be defeated if one has reason to think that one's perceptual faculties are not operating reliably.

\section{The conversion objection}

Does conservatism allow improper epistemic conversions? We have already discussed how one might be rational in holding a memory belief even if one acquired the belief improperly (as in the Hannibal case). This sort of epistemic conversion, due to the forgetting of one's previous evidence and counterevidence, I take to be unproblematic. However, conservatism applies to all beliefs, even beliefs where there is no such forgetting. Suppose that, prior to believing that $p, \mathrm{I}$ lack adequate reasons or grounds to believe $p$, and so am not rational to believe it. But suppose that I do not appreciate the inadequacy of my reasons and proceed to form the belief that $p$. If conservatism is correct, this means that the epistemic standards I must now meet are lower. For now I am prima facie rational, whereas before believing I wasn't. If I don't have any reason to give up my belief, then even if I remember what my reasons were (still incorrectly thinking they were good ones), I become ultima facie rational in believing that $p$. Could mere belief be as efficacious epistemically as that?

One can devise similar problems for certain other epistemological theories that invoke prima facie epistemic statuses. Arguably, our desires and expectations can affect how things look to us. So, suppose my desire that my baby's eyes be brown like mine affects how they appear to me. Now, just because they look brown to me, does it follow that, if I don't recognize the influence of my desires, I am rational to believe they are brown? One wants to say no. Similarly, if my desires, unbeknownst to me, are the source of my apparent rational intuition that $p$, it seems at least problematic to claim that that intuition makes me rational in believing that $p$. 
But conservatives seem to face a wider array of counterexamples. After all, conservatives take the fact that one holds a belief to confer positive epistemic status, and beliefs can be and are regularly based on bad reasons, often due to the improper influence of conative states. How things look, sound, feel, etc., and even how things intuitively seem are not hostage, at least to the same degree, to these bad influences.

I think the conservative's best response here is to broaden the range of defeating conditions. Consider again the case of forming a belief using gambler's fallacy reasoning. The subject seems not to be rational because the subject has, so to speak, all the materials for a defeater. He remembers the reasons he used in forming the belief, and though he thinks they were good, he has all the information right there in his current perspective needed to build a defeater. The defeater is something like: the reasoning I used to arrive at this belief is no good. ${ }^{34}$ Compare the Hannibal case. Here the subject seems perfectly rational to retain his belief. There is a defeater for his belief (i.e., that he formed it on such and such poor basis), but the materials for this defeater are long gone for the subject. My thought, then, is that defeaters, possessed or not, which are "constructible" from materials in one's current perspective are potential defeating conditions.

A note on my terminology. In speaking of defeaters for a subject's belief I have in mind special reasons for the subject to abandon the belief. In principle, then, defeaters needn't be possessed. We should be careful about 'possession', though. Where D is a defeater for a subject's $S$ 's belief that $p$, I'll speak of $S$ as possessing D iff, (i), D is evidence which $S$ has, and

\footnotetext{
${ }^{34}$ Facts about conative states, too, might count as defeaters constructible from one's current perspective. That one has a strong dislike of Texans and wants to believe the worst of them might be a defeater for a belief that a particular Texan has some bad characteristic.
} 
(ii), $S$ appreciates the reason-giving force of $\mathrm{D}$ in relation to her belief that $p .{ }^{35}$ So, someone who is aware that the lighting conditions are abnormal but doesn't appreciate the fact that this calls into question her belief that the object she sees is blue does not possess this defeater. In speaking of defeating conditions, I have in mind conditions whose absence is necessary for the relevant source X (in our case belief) to confer rationality and whose presence is consistent with the presence of $\mathbf{X}$. The set $\mathbf{D}$ of defeating conditions associated with such a source $\mathrm{X}$ is just the set such that $\mathrm{X}$ confers rationality iff $\mathrm{X}$ is present and all of D's members fail to obtain.

These definitions do not guarantee that the only sort of defeating condition is the possession of a defeater. What I am suggesting in this section is precisely that defeating conditions may include the existence of certain unpossessed defeaters.

What is it for a defeater to be constructible from materials in the subject's perspective? Here is a worry. Frege accepted Axiom V. He also had beliefs which, as Russell showed, could be used to build a defeater for Axiom V. Was the Russell-defeater constructible from materials in Frege's perspective? If so, then we would have to say that Frege wasn't rational in believing Axiom V before Russell presented his paradox to him. And that is unacceptable.

I suggest that we understand 'constructible' in terms of the admittedly vague notion of the simple exercise of properly functioning human cognitive capacities. There was no defeater constructible in the relevant sense for Frege because it took brilliance, not just the simple exercise of properly functioning human cognitive capacities, to construct it. However, in the case of reasoning based on affirming the consequent or when one "jumps to conclusions" or, at

\footnotetext{
35 'Appreciates' should be understood broadly, to require only proper sensitivity to the reason-giving force of the defeater and not outright belief that it has reason-giving force. Proper sensitivity to reason-giving force involves something like being prepared to revise one's beliefs appropriately in the face of the defeater.
} 
least arguably, when one is reasoning in accord with the gambler's fallacy, nothing like brilliance is necessary. ${ }^{36}$

Given all this, the conversion problem would then be addressed as follows: in the problematic cases, there is a defeater constructible from materials in the subject's current epistemic perspective; and this is why the subject's prima facie rationality to retain his belief is defeated.

This proposal is admittedly a first start. However, I would say that anyone wishing to make out the distinction between rational belief and blameless belief must appeal to defeating conditions going beyond defeaters possessed by the subject. And, to be adequate, such account should not count beliefs like the Hannibal belief as irrational. The only way to navigate between the Scylla and the Charybdis, I think, is to appeal to defeating factors in some sense present in the subject's perspective. My proposal can be thought of as one way of doing this, a way which ties the defeating power of such factors to the notion of a defeater: a defeating factor is present in the subject's perspective if the factor is a defeater for the subject's belief and the subject has in his current perspective all the materials for constructing it. ${ }^{37}$

\section{The "extra boost" objection}

\footnotetext{
${ }^{36}$ The idea is not that the actual subject is rational to believe whatever a well-functioning human counterpart would believe. That would generate counterexamples (since, e.g., the corrected subject would believe he has a good grasp of probability, that his judgments of the evidence are not at all influenced by prejudice). The notion of the simple exercise of properly functioning human cognitive capacities is used only for the purposes of determining, to put it intuitively, just how much work it must take to put together a defeater working from elements of the subject's perspective.

${ }^{37}$ An alternative approach, inspired by thinking about Burge's epistemology (though in ways Burge himself would likely dispute), invokes instead third-party inquirers who under philosophical reflection attempt to build a case for $p$ on the basis of premises about the mental states making up the subject's perspective, taking into account only the natures of those states and the conditions of their possibility. On reflection, such a reasoner would, arguably(!), see it as essential to the nature of beliefs that they are prima facie well-formed and maintained. But when the subject believes $p$ given only scanty evidence, third-party reasoners will have a reason to think that the subject's belief is not well-formed and maintained. The conversion objection is then answered by saying that because these third-parties would possess such reasons, the subject's prima facie rationality for retaining the belief is defeated.
} 
Like the conversion problem, the "extra boost" problem raises doubts about the epistemic efficacy of mere belief. Michael Huemer $(1999,348)$ raises this sort of objection as a problem for the view he calls "foundationalism" (and we call nondoxastic evidentialism) about the rationality of memory beliefs. If, prior to belief, I have good evidence for $p$, do I acquire another piece of good evidence - namely that I recall that $p$-- after believing that $p$ ? We're invited to answer: no. Now, conservatism does not count one's believing that $p$ as a piece of evidence which makes that belief itself rational. But conservatism does hold that believing, in the absence of defeating conditions, makes one rational to continue believing. The worry might then be that, in the absence of defeating conditions, the positive epistemic status conferred by belief could combine with the positive epistemic status conferred by retained evidence to give the subject an undue extra epistemic boost (Foley 1983, 176-7).

This problem is not unique to conservatism. There is a close parallel for testimony. Compare two cases. In the first, you simply tell me not to expect many birds at my birdfeeder in the summertime. I believe what you say. In the second, you are sharing with me your deliberations about whether I should expect many birds at my birdfeeder in the summertime: "Hmm. In the summertime, there are worms, bugs, etc. for the birds to eat. I don't think they'd bother with the birdfeeder much." You then say, confidently: "Yes. For those reasons, you shouldn't expect many birds at your birdfeeder in summer." Here I learn your evidence and then I learn that this evidence led to your belief. I see that it is good enough for rational belief. Do I gain an epistemic boost - beyond that provided by knowing your evidence - to believe the target claim because I now know that you formed the belief (let alone because I know that you expressed your belief by testifying)? 
Those who think that recipients are prima facie rational to believe what they are told (or what others believe) will be inclined to answer that in the first case you do derive an epistemic boost. But few, I imagine, will be inclined to think the same about the second case. You could gain a boost in the second case, it seems, only if you had some special reason to think that the testifier is a better evaluator of those reasons (that she is a birdwatcher, e.g.).

I think that something similar is true of one's relation to one's own beliefs. If one holds a belief that $p$ for which one has forgotten one's original evidence and lacks defeaters as well as the materials to construct defeaters, then one is rational in retaining the belief that $p$. But when I know what my earlier evidence was, it seems that the fact that I happen to now believe that $p$ does not improve my epistemic standing with respect to $p$. It does not, for example, make a stronger degree of conviction rational for me.

Now, one way of addressing these considerations - both in the testimony case as well as the memory case - is to say that once a subject is rational in believing something by virtue of one source X, adding a further rationality-conferring source Y needn't result in an epistemic boost for the subject. I know that Lincoln is the capital of Nebraska. If you then tell me it is, I don't gain any boost, even though your telling me facts does give me a boost in other circumstances. The mathematics of rational entitlement is not as simple as that. Perhaps, then, the "extra boost" worry is no real problem for conservatism. Perhaps the relevant examples are merely cases of epistemic overdetermination, i.e., the presence of two epistemic sources which are individually sufficient for positive epistemic status and whose combination provides no epistemic boost over what would be provided by each had the other not occurred.

However, I do not want to insist on this reply. So, I will close this section by discussing two ways to modify conservatism to avoid the attribution of an extra epistemic boost, assuming 
that epistemic overdetermination reply fails. One is to modify the claim about what is confers rationality, and the other is to further expand the range of potential defeating conditions. Taking the first approach, one would, strictly speaking, abandon conservatism in favor of a close cousin. Mere belief isn't epistemically efficacious, but belief in the absence of special information about past evidence $i$ s. Taking the second approach, one would flesh out the prima facie rider in something like the following way: if $S$ believes that $p$, then $S$ is rational in retaining the belief that $p$ provided and only provided that, (i), $S$ lacks defeaters for her belief; (ii), $S$ lacks the materials for constructing such a defeater, and (iii) $S$ lacks special information about her past evidence.

There are reasons, I think, to favor the second approach. How can we distinguish sources of positive epistemic status from enabling conditions for such sources? Audi (1993, pp. 8-9) suggests that a source should be a presence from which the positive status derives, rather than an absence of something to which the status is vulnerable. On this score, the second approach above is best: lacking special information about past evidence is not a presence but an absence of something that when present seems to preclude an epistemic boost. Alston (1988) suggests that a source should be something that could be legitimately cited in an argument as a factor in support of the truth of the proposition in question. Lacking special information about past evidence seems not to meet this condition. Finally, it might be suggested that a source should be something a subject could in some sense rely on in forming or retaining a belief. The mere fact (as opposed to the belief) that one lacks certain information is not the right sort of thing for one to rely on in retaining one's belief. ${ }^{38}$ Compare testimony again. The three considerations just

\footnotetext{
${ }^{38}$ Does believing that $p$ satisfy these three criteria? Arguably, yes. It is a presence that the subject's rational boost derives from, rather than an absence of something to which the rational boost is vulnerable. It is also a factor that could be cited in favor of the truth of the proposition. And there is a sense, I suggest, in which a subject relies on
} 
mentioned favor treating the lack of special information about a testifier's evidence as an enabling condition rather than an epistemic source.

But, in the end, I suspect the question about what confers rationality is not of paramount importance. Consider the schema below:

CONSV: $\quad$ If $S$ believes that $p$, then $S$ is rational to retain the belief that $p$ iff C obtains.

I take it that conservatism is vindicated if we can specify a condition $\mathrm{C}$ which, (a), includes nothing about the having of special positive evidence for $p$, or the rationality of the original formation and past retention of the belief that $p$, and (b) makes CONSV come out non-trivially true. I do not claim that I have succeeded in specifying such a $\mathrm{C}$. But I do claim that if the epistemic overdetermination response to the "extra boost" objection fails, the conservative can plausibly answer the objection by taking $\mathrm{C}$ to include conditions about the lacking of information about past evidence. $^{39} 40$

her past belief when she simply retains her belief. Such reliance is not a matter of an inference or quasi-inference from evidence, though.

${ }^{39}$ More tweaking is probably needed here. One might think that, on the one hand, if I have only very little information about the origin of my belief I ought to get some epistemic boost for having the belief, while also thinking that, on the other hand, the more such information I have, the less of a boost I should enjoy. These intuitions could perhaps be accommodated if we help ourselves to two sorts of measures: a measure of rational appropriateness and a measure of a subject's information about past evidence. For then we could propose that

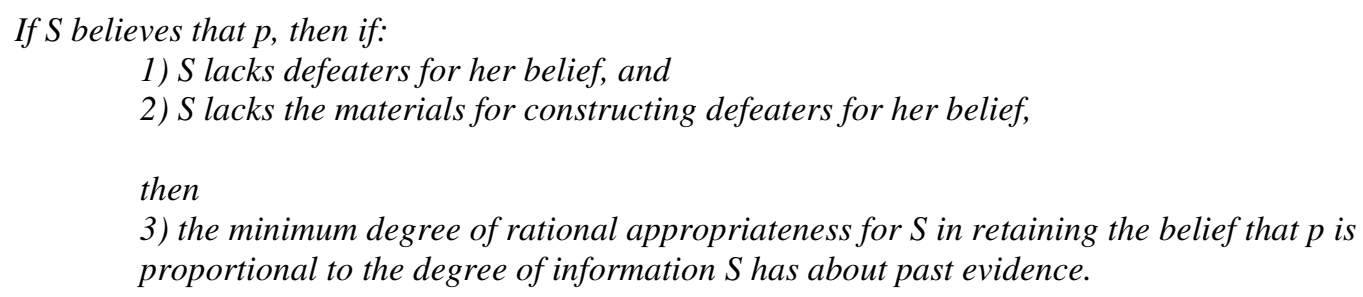

I use the term 'minimal' because $S$ might have just acquired new evidence for $p$. Depending on the quality of the new evidence, $S$ might gain a bigger boost.

I assume that those who accept a prima facie entitlement to believe what one is told (or what another believes) could similarly accommodate intuitions about the degree of boosts from testimony. The idea would be that the more information one has about the evidence had by one's testifier (and perhaps others in the testimonial chain) the less the minimally guaranteed epistemic boost for the recipient.

${ }^{40}$ A referee describes the following case. You remember that you have seen your brother-in-law John with an unfamiliar lady on several occasions in the past. According to conservatism, you do not get an epistemic boost by 
It should now be clear that a properly honed conservatism must be closely associated with long-stored memory beliefs. We have arrived at a form of conservatism according to which believing a proposition provides an epistemic boost to a subject only when the subject lacks defeaters, lacks the materials for defeaters, and lacks special information about her past evidence. In ordinary mature adults, long-stored memory beliefs comprise the bulk of beliefs which meet all of these conditions. This is the sense in which epistemic conservatism makes a good epistemology of memory belief.

\section{Concluding Remarks}

I have argued that the two standard accounts of the rationality of memory beliefs, preservationism and evidentialism, are inadequate. Preservationism wrongly separates the question of whether it is rational to abandon a belief from the question of whether abandoning it makes sense from one's current perspective. The preservationist must say that there are pairs of beliefs such that one rationally should be abandoned and the other rationally shouldn't, but that nothing in one's perspective favors doing one over the other. This is unacceptable. The evidentialist attempts to find evidence to ground not merely all cases of rational belief

forming the belief that John is cheating on your sister. But if you form the belief and then quickly take a pill that erases these memories, then you will get a boost. Isn't this counterintuitive? It is, but its counterintuitiveness can be mitigated. First, note that conservatism doesn't imply that you are more rational in one case than in the other. Second, and more importantly, note that there are other positive epistemic statuses which you enjoy in the first case but not in the second, e.g., knowledge or at least reliability, sensitivity, safety, etc. You may not lose out with respect to epistemic rationality in the second case, but you do lose out with respect to these other statuses.

It should also be noted that similar problems arise for other more standard views under which rationality is defeasible (see Elgin 1988). Suppose I have good reasons for a belief about tax policy, a belief which it is also convenient for me to hold given my income level. But suppose that I do not hold it on the basis of wishful thinking. The belief is rational, by most accounts. Then I learn that if I read a certain economist's paper, I might well change my mind. So, I choose not to read the paper, and then take a pill to make me forget the whole episode. On standard accounts, I can come once again to have a rational belief. This seems strange initially but less so, I think, after we reflect on what has been lost: the chance to have other epistemic goods, including true belief, knowledge, reliable belief, better understanding of issues, etc. 
acquisition but all cases of rational belief retention. This is to rest too much weight on the possession of evidence. Evidence for many of our memory beliefs is just in too short a supply. Epistemic conservatism avoids these problems. It makes the rationality of belief retention a matter of one's current perspective, unlike preservationism. And it severs the strong connection asserted by evidentialists between rational belief and the possession of evidence in favor of what one believes. While rational belief formation arguably depends on the possession of good evidence rational belief retention in general does not. Finally, three of the best objections against epistemic conservatism can be answered. The partiality problem is answered by noting that conservatism can be grounded in a Reidian principle concerning the trustworthiness of beliefs in general, and perhaps ultimately, as Burge would have it, in terms of fundamental a priori relations between content, belief, rationality, and truth. The problem of mere belief generating illicit conversions in epistemic status is answered by broadening the scope of defeating conditions to include defeaters constructible from elements of one's current perspective. Finally, the problem of gaining an undue extra epistemic boost upon forming a belief can answered either by pleading epistemic overdetermination or by further broadening the range of defeating conditions to include having special information about one's past evidence for the belief.

Epistemic conservatism does not deserve its bad reputation. When we construe defeating conditions properly, the doctrine is a modest and sensible one. Some will say that the resulting view is so modest as not to deserve the provocative label 'epistemic conservatism'. Call it what you like, it is an epistemological position with decidedly conservative elements, and it is a position worth taking seriously. ${ }^{41}$

\footnotetext{
${ }^{41}$ This paper has been a long time in coming. A warm thanks goes to David Christensen, Jeremy Fantl, Peter Graham, Robert Howell, Jonathan Kvanvig, Jennifer Lackey, Justin McBrayer and especially Peter Markie, whose
} 


\section{Sources}

Alston, William 1988. “An Internalist Externalism.” Synthese, 74: 265-283.

Annis, David B. 1980. "Memory and Justification." Philosophy and Phenomenological

Research 40, 3: 324-33.

Audi, Robert 1993. The Structure of Justification. New York: Cambridge. 2001. The Architecture of Reason. New York: Oxford.

Baddeley, Alan D. 1999. Essentials of Human Memory. Psychological Press.

Burge, Tyler 1993. "Content Preservation." The Philosophical Review 102;4: 457-88. 1997. "Interlocution, Perception, and Memory." Philosophical Studies 86: 21-47.

2003b. "Memory and Persons." Philosophical Review 112; 3: 289-337.

2003a. "Perceptual Entitlement." Philosophy and Phenomenological Research 67: 503-48.

Chisholm, Roderick 1989. Theory of Knowledge, $3^{\text {rd }}$ ed. Englewood Cliffs, NJ: Prentice-Hall.

Christensen, David 1994. "Conservatism in Epistemology." Nous 28. 1: 69-89. and Kornblith, Hilary 1997. "Testimony, Memory and the Limits of the A Priori." Philosophical Studies 86:1-20.

2000. "Diachronic Coherence versus Epistemic Impartiality." The Philosophical Review 109.3: 349-371.

Dokic, Jérome 2001. "Is Memory merely Preservative?" in Time and Memory: Issues in Philosophy and Psychology, ed. Hoerl, C. and McCormack, T. New York: Oxford: 21332.

Edwards, Jim 2000. "Burge on Testimony and Memory." Analysis 60, 1: 124-31.

Elgin, Catherine 1988. "The Epistemic Efficacy of Stupidity." Synthese 74: 297-311.

Feldman, Richard and Conee, Earl 1985. "Evidentialism," in Philosophical Studies 48: 15-34. and Conee, Earl 2002. "Internalism Defended," American Philosophical Quarterly 38 (2001): 1-18. Also in Epistemology: Internalism and Externalism, edited by Hilary Kornblith, Blackwell, 2001, pp. 231-260.

2001. "Voluntary Belief and Epistemic Evaluation," Knowledge, Truth, and Duty: Essays on Epistemic Justification, Responsibility, and Virtue, edited by Matthias Steup, Oxford: Oxford University Press, 77-92.

Foley, Richard 1983. "Epistemic Conservatism." Philosophical Studies 43: 165-82. 1993. Working without a Net. New York: Oxford University Press. 2001. "The Foundational Role of Epistemology in a General Theory of Rationality." In A. Fairweather and L. Zagzebski (eds.), Virtue Epistemology: Essays on Epistemic Value and Responsibility. New York: Oxford. 214-230.

Fricker, Elizabeth manuscript. "Knowledge from Trust in Testimony is Second-Hand Knowledge." Paper delivered at the 2005 Rutgers Epistemology Conference.

Fumerton, Richard, 1995. Metaepistemology and Skepticism. London, Rowman and Littlefield.

Goldman, Alvin 1999. “Internalism Exposed,” Journal of Philosophy 96: 271-293.

sets of comments nearly sank the project of the paper at several points. Thanks also to audiences at the University of Vermont, the University of Missouri at St. Louis, and SMU. This paper was based on research supported by a University of Missouri Research Board grant. 
1976. "What is Justified Belief?" Reprinted in E. Sosa and J. Kim (eds.),

Epistemology: An Anthology. New York: Blackwell, 1999: 340-353.

Haack, Susan 1995. Knowledge and Inquiry. Place? Blackwell.

Harman, Gilbert 1986. Change in View: Principles of Reasoning. Cambridge, MA: MIT

Huemer, Michael 1999. "The Problem of Memory Knowledge." Pacific Philosophical

Quarterly 80: 346-57.

2001 Skepticism and the Veil of Perception. Landam, MA: Rowman \& Littlefield.

Johnston, Mark 2004. "The Obscure Object of Hallucination," Philosophical Studies vol. 120/13: 113-183.

Kvanvig, Jonathan 2003. "Propositionalism and the Perspectival Character of Justification." American Philosophical Quarterly 40.1: 2-18.

Locke, Don 1971. Memory. Garden City, NY: Doubleday.

Lycan, William 1988. Judgement and Justification. New York: Cambridge.

Malcolm, Norman 1963. "A Definition of Factual Memory.” In Knowledge and Certainty. Englewood Cliffs, NJ: Prentice-Hall, Inc: 222-240.

Owens, David 2000. Reason without Freedom: The problem of epistemic normativity. London: Routledge.

Plantinga, Alvin 1993. Warrant and Proper Function. New York: Oxford.

Pollock, John 1974. Knowledge and Justification. Princeton, NJ: Princeton. 1986. Contemporary Theories of Knowledge. Totowa, NJ: Rowman and Littlefield.

Reid, Thomas 1969. Essays on the Intellectual Powers of Man. Cambridge, MA: MIT Press.

Senor, Thomas 1993. "Internalistic Foundationalism and the Justification of Memory Belief." Synthese 94: 453-76.

2005. "The Epistemological Problems of Memory." Stanford Encyclopedia of Philosophy.

Shoemaker, Syndey 1972. "Memory." In P. Edwards (ed) Encyclopedia of Philosophy. New York: Macmillan, vol. V, 265-274.

Sklar, Lawrence 1975. "Methodological Conservatism." The Philosophical Review 84, 3: 374400.

Sosa, Ernest 2000. "Skepticism and the Internal/External Divide.” In E. Sosa and J. Greco (eds.) The Blackwell Guide to Epistemology, 145-157. Blackwell: Malden, MA.

Van Fraassen 1984. "Belief and the Will." The Journal of Philosophy 81: 235-56. 